\title{
Symposium on 'Nutrition and health in children and adolescents' Session 5: Risk and management of food allergy in children
}

\section{Dietary management of food allergy in children}

\author{
Kate E. C. Grimshaw \\ University Child Health, University of Southampton, Southampton General Hospital, Tremona Road, \\ Southampton SO16 6YD, UK
}

\begin{abstract}
Currently, the only treatment for any food hypersensitivity (including food allergy) is the dietary avoidance of the causative allergen, using an elimination diet. In addition to being used for the management of food hypersensitivity, an elimination diet may also be used in the diagnosis of food allergy. Dietary exclusion should be managed by a dietitian or other health professional with nutritional expertise to ensure that the exclusion does not lead to a nutritionally-deficient diet. There are three main types of elimination diets: single-food exclusion; multiple-food exclusion; the 'few-food' diet, which requires the avoidance of a large number of allergens and therefore concentrates on the foods that can be included rather than the foods that need to be avoided. Any sort of elimination diet is hard to manage. Thus, as well as ensuring that the diet is nutritionally adequate, it is essential that families are given advice and support relevant to their circumstances to aid them in the day-to-day management of the diet, so that it remains varied and enjoyable for food-allergy sufferers. This approach involves advice about which alternative foods are available, provision of 'free-from' recipes and guidance on which nutritional supplements are needed to meet their nutritional needs.
\end{abstract}

Food allergy: Dietary management: Elimination diets: Children's nutrition

\begin{abstract}
Allergic disease is increasing in populations throughout the world, and more so in developed countries than in developing countries. In the UK allergic disease currently accounts for $6 \%$ of general practice consultations and $10 \%$ of the prescribing budget (Royal College of Physicians, 2003). Food allergy is also increasing (Grundy et al. 2002), but there is confusion as to what constitutes a food allergy and how it should best be diagnosed. To try and improve the understanding of food allergy, the Nomenclature Review Committee of the World Allergy Organization has issued a report proposing revised nomenclature for allergy (Johansson et al. 2004). This report states that any reaction to food that causes objectively reproducible symptoms or signs, even when the food is eaten unknowingly (blind), should be described as food hypersensitivity. If immunological mechanisms can be demonstrated, then the reaction can be described as a food allergy. If IgE is involved in the reaction, then the term IgE-mediated food allergy
\end{abstract}

should be used. All other reactions should be described as non-allergic food hypersensitivity. These reactions have previously been described as food intolerance.

Currently, the only treatment for any food hypersensitivity is dietary avoidance of the causative allergen, using an elimination diet. There are different types of elimination diets, ranging from those that only eliminate one food (e.g. egg, milk, kiwi fruit (Actinidia chinensis Planch.) from the diet (simple food-exclusion diet) to those that eliminate a number of foods (multiple-food-exclusion diet; e.g. egg-, milk-, wheat- and soya-free diet), and in some circumstances so many foods are implicated in causing hypersensitivity symptoms that it is easier to consider which foods are allowed in the diet ('few-food' diet). In addition to being used for the management of food hypersensitivity, an elimination diet may be used in the diagnosis of food allergy. Whatever the reason for dietary restriction it is essential that the clinical symptoms are severe enough to 
Table 1. General composition of a multiple-food-exclusion diet

\begin{tabular}{|c|c|c|}
\hline $\begin{array}{l}\text { Foods usually } \\
\text { excluded }\end{array}$ & $\begin{array}{l}\text { Foods sometimes } \\
\text { excluded }\end{array}$ & $\begin{array}{l}\text { Foods usually } \\
\text { permitted }\end{array}$ \\
\hline $\begin{array}{l}\text { Milk and milk } \\
\text { products } \\
\text { Eggs } \\
\text { Wheat } \\
\text { Citrus fruit }\end{array}$ & $\begin{array}{l}\text { Pork, bacon, } \\
\text { liver and offal } \\
\text { Fish and shellfish } \\
\text { Barley, oats, maize, rye } \\
\text { Nuts, seeds and pips } \\
\text { Potatoes, tomatoes, } \\
\text { onions and garlic } \\
\text { Chocolate } \\
\text { Coffee or tea } \\
\text { Food colourings } \\
\text { (especially azo-dyes) } \\
\text { Food preservatives } \\
\text { (especially benzoates } \\
\text { and sulfites) } \\
\text { Soya }\end{array}$ & $\begin{array}{l}\text { Beef, lamb, } \\
\text { turkey, rabbit } \\
\text { Rice } \\
\text { Sugar, treacle, } \\
\quad \text { syrup } \\
\text { Lard } \\
\text { Fruit (except } \\
\text { citrus fruit) }\end{array}$ \\
\hline
\end{tabular}

warrant dietary treatment, as any type of dietary manipulation requires considerable effort on the part of the family.

\section{Elimination (exclusion) diets}

\section{Elimination diets for diagnosis}

Often (particularly in non-IgE-mediated food allergy and non-allergic food hypersensitivity reactions) it is not obvious which foods may be causing the symptoms. In this case a diet that eliminates the suspected foods is prescribed. The length of time needed to establish a diagnosis will depend on the frequency of symptoms, how strict the diet is and type of symptoms involved (improvement in gastrointestinal symptoms may occur within 1 or $2 \mathrm{~d}$, whereas improvement in eczema may take several weeks). If successful, the diet will result in a marked relief of symptoms.

Simple food-exclusion diet. This diet excludes a single food or food constituent. When reactions are quick it is easy to identify the provoking food, and exclusion may be quite straightforward for foods such as strawberries, chocolate and shellfish. However, the sources of wheat, milk, egg or azo-dyes in food are less obvious and dietary avoidance advice needs to be more detailed to ensure complete elimination is achieved.

Multiple-food-exclusion diet. In this diet a number of foods commonly considered to be allergenic are excluded from the diet. There is no standard elimination diet that is guaranteed to eliminate all suspect foods for all patients, so the diet often eliminates a combination of those known to commonly elicit an allergic reaction and those that are indicated by taking a dietary history (for details of the general composition of a multiple-food-exclusion diet, see Table 1).

The diet is usually followed for a period of 2-3 weeks, although in conditions where there is a natural fluctuation in disease state, as is the case for eczema, it may be necessary to continue the diet for $\leq 6$ weeks. If improvement
Table 2. Two examples ( $A$ and $B$ ) of the 'few-food' diet and the food groups included in the less-restricted 'few-food' diet (two foods to be chosen from each food group)

\begin{tabular}{|c|c|c|}
\hline $\begin{array}{l}\text { 'Few-food' } \\
\text { diet ... }\end{array}$ & A & B \\
\hline & $\begin{array}{l}\text { Turkey } \\
\text { Cabbage, sprouts, } \\
\text { broccoli, cauliflower } \\
\text { Potato, potato flour } \\
\text { Banana } \\
\text { Soyabean oil } \\
\text { Tap water }\end{array}$ & $\begin{array}{l}\text { Lamb } \\
\text { Carrots, } \\
\quad \text { parsnips } \\
\text { Rice, rice flour } \\
\text { Pear } \\
\text { Sunflower oil } \\
\text { Tap water }\end{array}$ \\
\hline \multicolumn{3}{|l|}{$\begin{array}{l}\text { Less-restricted } \\
\text { 'few-food' diet }\end{array}$} \\
\hline Meat & $\begin{array}{l}\text { Lamb, rabbit, turkey, } \\
\text { pork }\end{array}$ & \\
\hline Starchy food & $\begin{array}{l}\text { Rice, potato, } \\
\text { sweet potato } \\
\text { (Ipomoea batatas } \\
\text { (L.) Lam.) }\end{array}$ & \\
\hline Vegetables & $\begin{array}{l}\text { Broccoli, cauliflower, } \\
\text { cabbage, Brussel } \\
\text { sprouts, carrots, } \\
\text { parsnips, celery, } \\
\text { cucumber, marrow, } \\
\text { courgettes (Cucurbita } \\
\text { pepo), } \\
\text { leeks, onions, asparagus }\end{array}$ & \\
\hline Fruit & $\begin{array}{l}\text { Pears, bananas, peaches } \\
\text { and apricots, pineapples, } \\
\text { melon }\end{array}$ & \\
\hline
\end{tabular}

occurs, foods then need to be reintroduced to establish which ones have provoked symptoms. Failure to respond to a multiple-food-exclusion diet does not immediately rule out the possibility of food allergy or intolerance. To rule out food allergy or intolerance it must be ascertained whether the patient has followed the exclusion procedure accurately, and it must be established that the allergy or intolerance is not to a food that was included in the exclusion diet.

'Few-food' diet. In practice, the avoidance of a large number of foods can be difficult for the patient and carer, and for the dietitians to achieve. It is, therefore, much easier to consider the foods that can be eaten, which is the basis of the 'few-food' diet. However, because of the very restrictive nature of the diet, it should not be followed for $>3-4$ weeks. The diet usually consists of one meat, one carbohydrate source, one fruit and one vegetable (see Table 2). If improvement is not seen on this regimen, a different set of foods can be used. Less-restricted diets (see Table 2) can be used in which two meats, vegetables and fruits can be eaten.

Re-introduction of foods. The sufferer or the parent of a child who has experienced marked relief of symptoms on a diet will usually want to continue with it, but ineffective diets must be abandoned. An infant who is doing well on a cow's milk-free formula is generally not introduced to cow's milk for 9-12 months. In the meantime, the infant should be weaned onto milk-free weaning foods. 
For an older child, if the initial diet avoids several foods, these foods should be re-introduced singly in order to try and identify trigger foods. Where there is a perceived risk of a severe reaction to a food, re-introduction of that food should be given in hospital as a food challenge. Where the reactions are less severe, each new food may be introduced in a small quantity at home, then given in a normal amount every day for 1 week and then incorporated into the diet as desired. The order of re-introduction should depend on the individual's preferences and the need for nutritional adequacy.

Food challenges. Children tend to grow out of some specific food allergies (e.g. milk, egg, wheat, soya), but are less likely to grow out of others (peanuts, tree nuts, fish, shellfish), and so food re-introductions will need to be considered from time to time. If there is a potential for a severe reaction on re-introduction of the food, challenges should be performed under professional supervision in experienced hospital units. The gold standard for confirming or refuting food allergy is the double-blind placebocontrolled food challenge (Bock et al. 1988). Although this technique is necessary for research, open challenges are more common in practice. However, many children are very reluctant to eat a new food, or one they have previously been told to avoid. It is therefore often advisable to provide the challenge in a single-blind form simply to ensure that the child consumes it.

Thus, the challenge generally consists of a food that is eaten without symptoms (e.g. yoghurt, biscuit, milk substitute) into which the suspected food has been added. Each dose is given 15-30 min apart, starting with a tiny dose (e.g. the size of a pinhead) and increasing the dose by doubling it until the child has eaten a 'normal' portion of the food. The child's blood pressure and pulse are taken between doses, and the child is monitored for other signs of an allergic reaction (e.g. rash, urticaria).

Maintenance diet. The maintenance diet is achieved when the re-introduction of all foods has been attempted and the child is having the widest possible variety of foods. Nutritional adequacy is paramount and dietary supplements are sometimes necessary. For example, children without milk in their diet generally need a Ca supplement (Hill \& Hosking, 1995). The dietitian plays a vital role in ensuring that individuals know how to avoid the necessary foods, suggesting alternatives to avoided foods, giving recipes and meal plans where necessary and ensuring adequacy and enjoyment of the diet.

\section{Elimination diets for treatment}

An elimination diet remains the only treatment for food hypersensitivity. The basis of the avoidance advice given is the same regardless of the mechanism involved, but the 'strictness' of the avoidance diet is affected by the symptoms caused. For a child prone to anaphylaxis in response to small amounts of the food, avoidance needs to be strict. For those children who have non-IgE-mediated food allergy or non-allergic food hypersensitivity reactions the avoidance does not need to be as strict, as small amounts of the allergen can generally be tolerated without adverse symptoms. No dietary manipulation is easy, so it is the role of the dietitian to not only give information on how to avoid the causative food, but also on how to make the resultant diet as palatable as possible.

\section{Foods that commonly cause hypersensitivity reactions}

Although any food can theoretically cause a hypersensitivity reaction, there are a small number of foods that cause the majority of reactions. The majority of reactions to foods in infants and young children will be to egg and milk. It has long been established that most children grow out of these allergies (Sampson \& Scanlon, 1989). However, it is commonly thought that peanut allergy does not resolve, although Skolnick et al. (2001) have shown that peanut allergy may be outgrown in $21.5 \%$ of patients. Tree nut, fish and shellfish allergies tend to develop in older children and are unlikely to be outgrown. Other foods that commonly cause reactions in children are soya, wheat, seeds and, to a lesser extent, fruits. Reactions to chocolate and azo dyes (artificial food colourings) are also often reported but they are not IgE mediated.

\section{Dietary management of food hypersensitivities}

The dietary management of food hypersensitivity consists primarily of educating patients and their families so that they can avoid the causative food while still meeting all nutritional requirements. Before any advice is given it is essential to consider how strict the diet needs to be. It is not necessary for a family to strive for complete avoidance of an allergen if reactions only occur when relatively large doses of the food are taken. On the other hand, when lifethreatening reactions occur to tiny doses, advice on complete avoidance is essential.

\section{Dietary-avoidance advice}

Information on the main sources of the food, the terms that may be used on labels for the food and the foods that may contain the allergen unexpectedly (i.e. 'hidden') is the mainstay of any dietary-avoidance advice. Additionally, the main nutrients provided by the food to be eliminated from the diet need to be considered to ensure that they are replaced by other foods allowed in the diet or by dietary supplements. Details of the nutrients provided by the five foods to which children most commonly react are detailed in Table 3 .

To be able to adequately manipulate diets to ensure that they are meeting the child's nutritional requirements, knowledge of the main sources of vitamins and minerals is essential (Table 4), so that other sources can be incorporated into the diet.

In addition to information on how to avoid a specific food, an essential part of the successful management of food allergy is the provision of information on what alternative foods are available and an explanation of labelling laws and common labelling practices. When strictly avoidance of a food is necessary, 'may contain' labelling and food contamination issues need to be discussed. 
Table 3. The commonest allergens to cause nutritional problems

\begin{tabular}{|c|c|c|c|c|}
\hline $\begin{array}{l}\text { Provoking } \\
\text { foods }\end{array}$ & Main sources & Other terms & Hidden sources & Main nutrients \\
\hline Cow's milk & $\begin{array}{l}\text { Most fat spreads, cheese, } \\
\text { yoghurts, ice creams, dairy } \\
\text { desserts }\end{array}$ & $\begin{array}{l}\text { Casein, caseinates, } \\
\text { lactose, whey, buttermilk }\end{array}$ & $\begin{array}{l}\text { Meat products, breakfast } \\
\text { cereals, nuts, gums, } \\
\text { sweeteners, nougat }\end{array}$ & $\begin{array}{l}\mathrm{Ca}, \mathrm{Mg}, \mathrm{P}, \mathrm{I} \text {, vitamins } \mathrm{A}, \mathrm{B}_{6} \\
\mathrm{~B}_{12} \text { and } \mathrm{D} \text {, riboflavin, } \\
\text { pantothenic acid }\end{array}$ \\
\hline Eggs & $\begin{array}{l}\text { Cakes, biscuits, speciality } \\
\text { breads, mayonnaise }\end{array}$ & $\begin{array}{l}\text { Albumen, egg lecithin, } \\
\text { lysozyme, globulin, } \\
\text { livetin, } \\
\text { simplesse }\end{array}$ & $\begin{array}{l}\text { Chocolates, ice cream, } \\
\text { cook-in-sauces, 'Quorn', } \\
\text { pastry, yoghurts, desserts }\end{array}$ & $\begin{array}{l}\text { Vitamin } B_{12} \text {, pantothenic acid, } \\
\text { folate, riboflavin, Se, biotin }\end{array}$ \\
\hline Wheat & $\begin{array}{l}\text { Breads, breakfast cereals, } \\
\text { pasta, cakes, biscuits, } \\
\text { batter }\end{array}$ & $\begin{array}{l}\text { Gluten, rusk, } \\
\text { breadcrumbs, } \\
\text { hydrolysed wheat } \\
\text { protein }\end{array}$ & $\begin{array}{l}\text { Yoghurts, processed cheese, } \\
\text { mayonnaise, beer, } \\
\text { chocolates, nuts, crisps }\end{array}$ & $\begin{array}{l}\text { Thiamin, riboflavin, niacin, } \mathrm{Fe} \text {, } \\
\qquad \mathrm{Se}, \mathrm{Cr}\end{array}$ \\
\hline Soya & $\begin{array}{l}\text { Meat substitutes, breads, soya } \\
\text { sauce, soya products }\end{array}$ & $\begin{array}{l}\text { Flavouring, hydrolysed } \\
\text { vegetable protein, } \\
\text { lecithin }\end{array}$ & Any processed food & $\begin{array}{l}\text { Thiamin, riboflavin, vitamin } \mathrm{B}_{6} \text {, } \\
\text { folate, } \mathrm{Ca}, \mathrm{P}, \mathrm{Mg}, \mathrm{Fe}, \mathrm{Zn}\end{array}$ \\
\hline Peanut & $\begin{array}{l}\text { Peanut butter, confectionery, } \\
\text { snacks, frozen desserts, } \\
\text { Asian dishes }\end{array}$ & Groundnut, arachis & $\begin{array}{l}\text { Not often 'hidden', but traces } \\
\text { can be found in some foods, } \\
\text { e.g. cereals and chocolates }\end{array}$ & $\mathrm{Mg}, \mathrm{Mn}, \mathrm{Cr}$, vitamin $\mathrm{E}$ \\
\hline Tree nuts & $\begin{array}{l}\text { Breakfast cereals, breads, } \\
\text { crackers, biscuits, cereals, } \\
\text { salads, } \\
\text { sauces, marzipan }\end{array}$ & Flavouring (in 'nutty' foods) & $\begin{array}{l}\text { Not often 'hidden', but traces } \\
\text { can be found in some foods, } \\
\text { e.g. cereals and chocolates }\end{array}$ & Depends on type of nut \\
\hline
\end{tabular}

Table 4. Main sources of vitamins and minerals

\begin{tabular}{|c|c|c|c|}
\hline Vitamin & Sources & Mineral & Sources \\
\hline Vitamin A & $\begin{array}{l}\text { Liver, whole milk, butter, margarine, eggs, carrots, dark } \\
\text { leafy vegetables }\end{array}$ & $\mathrm{Ca}$ & $\begin{array}{l}\text { Milk, cheese, yoghurt, bread, green vegetables, } \\
\text { canned fish }\end{array}$ \\
\hline Thiamin & Bread and other cereal products, potatoes, milk, meat & $\mathrm{Mg}$ & Milk, bread, cereal products, potatoes \\
\hline Riboflavin & Milk, meat, eggs, vegetables & $\mathrm{Na}$ & Table salt, bread, cereal products, meat, milk \\
\hline Niacin & Meat, potatoes, bread, fortified breakfast cereals & $\mathrm{K}$ & Vegetables, meat, milk, fruit and fruit juices \\
\hline Vitamin $\mathrm{B}_{6}$ & Meat, milk, potatoes and other vegetables & $\mathrm{Cl}$ & Table salt, seafood, milk, meat, eggs \\
\hline Vitamin $B_{12}$ & Offal, meat, milk and cheese, fish, eggs & $\mathrm{P}$ & Milk, bread, cereal products, meat \\
\hline Folic acid & Offal, meat, leafy vegetables, wholegrain cereals & $\mathrm{Fe}$ & $\begin{array}{l}\text { Meat, bread, flour and cereal products, potatoes, } \\
\text { vegetables }\end{array}$ \\
\hline Pantothenic acid & Meat, milk, cereals, pulses & $\mathrm{Zn}$ & Meat, milk, bread and cereal products \\
\hline Biotin & Offal, eggs, milk, cereals, fish, fruit and vegetables & $\mathrm{Cu}$ & Wholegrain cereals, meat, vegetables \\
\hline Vitamin C & Potatoes, fruit juice, citrus fruit, green vegetables & $\mathrm{FI}$ & Tea, fish, water \\
\hline Vitamin D & $\begin{array}{l}\text { U.V. light, butter, margarine, eggs, oily fish, breakfast } \\
\text { cereals }\end{array}$ & 1 & Milk, meat, eggs, fish \\
\hline \multirow[t]{3}{*}{ Vitamin $\mathrm{E}$} & $\begin{array}{l}\text { Vegetable oils, wholegrain cereals, eggs, dark leafy } \\
\text { vegetables }\end{array}$ & $\mathrm{Mb}$ & Legumes, cereals, grains \\
\hline & & $\mathrm{Se}$ & Cereals, fish, offal, meat, cheese, eggs, milk \\
\hline & & $\mathrm{Cr}$ & Cereals, meats, water \\
\hline
\end{tabular}

Alternative foods. The choice of alternative foods that are now readily available can make dietary exclusion easier. When explaining an avoidance diet to parents it is essential that they are given information on the products that are available so that good variety in the diet can be maintained. As many parents prefer to give their child the foods that are known to be safe, it is sometimes necessary to stress that new foods should be tried so that the diet continues to be interesting; they often do not understand that it is important to introduce new foods into their child's diet, in the same way as they would with a child without food allergies.
Advice should be given on the products that are available (e.g. milk substitutes, egg-free cakes, wheat-free pasta) from their supermarkets, local shops and even companies on the internet. Parents can be provided with lists of foods that are free from all the ingredients their child needs to avoid, as well as information about readilyavailable 'free-from' items that are not considered 'allergy' foods (e.g. puffed rice cakes, Thai rice noodles), and the customer helplines operated by most food manufacturers and supermarkets.

A general discussion about menu planning appropriate to the age of the child is helpful, including ideas for packed 
lunches and weaning foods, and recipes, which can also be very useful, e.g. cakes without egg, biscuits and cakes without wheat and gravy and sauces without wheat. Other carers may also need to be contacted, e.g. school caterers, nursery nurses and staff are generally very grateful for any advice relating to the management of the child's diet. Parents also appreciate some guidance on how to encourage a child to take a new food, such as using a covered mug or flavouring (e.g. milk shake powder, if allowed, considerably improves the taste of alternative milks and. other flavours such as jam, sauce may improve the initial acceptance of wheat-free products).

Labelling issues. New EU labelling laws to aid dietary avoidance (European Commission, 2003) came into effect in November 2005. Previously, a label was not required to state the presence of an ingredient if it made up $<25 \%$ of the final product, which led to many dietary indiscretions and subsequent reactions. The new labelling laws require the presence of twelve food allergens at any level to be stated on the label: celery; cereals containing gluten (wheat, barley, rye and oats); crustaceans; eggs, fish; milk; mustard; tree nuts; peanuts; sesame seeds; soyabeans; $\mathrm{SO}_{2}$ and sulfites (at levels $>10 \mathrm{mg} / \mathrm{kg}$ or $>10 \mathrm{mg} / \mathrm{l}$ ). However, foods that are not prepacked are not covered by this legislation, and it is important to ensure that patients and their families are aware of this situation. Where life-threatening reactions are involved, the safest option is often to buy only prepackaged foods. Food manufacturers and supermarkets produce 'free-from' lists for their products, which are very useful in managing avoidance diets, and patients or carers should be encouraged to use these lists to identify alternative products that can be included in the diet.

'May contain' and contamination risks. Another labelling issue that needs to be discussed, particularly when reactions to a food may be severe, is the 'may contain' label. This label causes confusion to patients and is often seen as defensive labelling that is used to legally protect a food company, which is generally not the case. It needs to be stressed that this label is used to warn that a food allergen may be present and should be taken seriously, as it is possible that occasionally the food may indeed contain the allergen in question; the food may have been eaten safely, but it is still possible that in the future it may cause a reaction.

Labels are currently providing more information to consumers in an effort to aid their risk-management decisions, e.g. 'made in a factory that uses nut ingredients but not on the same line'. However, consumers find it difficult to relate this information to the likelihood of the food containing nuts, and it is essential that these types of labels are explained to carers to ensure that as well as keeping the risk of a reaction to a minimum, the child is not receiving a diet that is unnecessarily restrictive.

The remaining issue that needs to be addressed when giving avoidance advice is contamination, which is particularly relevant when buying loose foods from bakeries, delicatessens and salad bars and when eating out. Making parents aware of the possibility of cross-contamination at home is equally important.

Obviously, where reactions only occur to large doses it is important to stress that there is no need to worry about contamination issues and 'may contain' labelling. This reassurance can make a real difference to the families involved.

Non-food sources. It is important that patients and carers are made aware of where else they may encounter the food that causes their reactions. Pharmaceuticals may contain food products, particularly milk. Cosmetics, toiletries and perfumes may also contain food ingredients, and thus allergens. Providing and explaining the terms used in labelling is useful, particularly for patients who have severe reactions or skin reactions.

Dietary supplements. When a food is eliminated from the diet, the diet may no longer meet nutritional requirements, and the risk of a nutritionally-inadequate diet increases with the number of foods that have to be avoided. By considering which main nutrients are provided by the eliminated food and then ensuring other dietary sources of that nutrient are incorporated into the diet, it is possible to ensure that the diet remains nutritionally adequate. These alternative sources of the nutrient can be provided by foods that are naturally rich in the nutrients, but they can also be provided by foods that have been fortified, such as breakfast cereals, bread, margarine, soya milk. Even if a wide range of alternative foods are taken in the diet, it is important not to assume that the diet is nutritionally adequate. Although a $24 \mathrm{~h}$ recall can give a good indication of a child's intake, it is often necessary to analyse a food diary kept by the family (for $\geq 3 \mathrm{~d}$ ) to assess the adequacy of the diet. If dietary supplementation is needed it is important to assess the dose required and the supplement that would be best accepted by the child. General practitioners are generally willing to prescribe supplements, but sometimes an over-the-counter product may be more readily accepted. If cost is not an issue to the family, it is useful to consider all suitable supplements.

\section{Follow-up}

It is essential that children following an exclusion diet are followed up regularly. Children's diets vary enormously as they get older, and nutritional requirements also change. There may also be advances in knowledge that may affect treatment strategies, and it is also important to ensure that as the child gets older they themselves understand their diet. Furthermore, families may not appreciate the importance of dietary review, as they assume once they have been instructed on the diet no further dietary input is needed. Thus, it is useful to explain to parents when they are first seen that dietary review is essential to ensure that the diet continues to meet the child's nutritional needs.

\section{Conclusion}

The dietary management of any food hypersensitivity needs to be tailored to each individual, taking into account the foods that need to be avoided, how strict the diet needs to be, the child's nutritional requirements and the foods that are likely to be eaten by the child. In addition, families are often very anxious about all the issues associated with 
the management of their child's condition, and may require additional information, including: when and how to use rescue medication; whether holidays should be taken and, if so, where they can go; how they can reduce the risk of any subsequent child developing an allergy; whether their child is likely to grow out of their condition. Thus, it is very difficult to deal with the dietary management of food hypersensitivity in isolation, and specialist allergy clinics staffed by a range of health professionals who specialise in allergy (e.g. nurses, consultants, dietitians, clinical psychologists) are the most effective way of empowering parents and children to feel in control of their condition, as opposed to feeling that it is controlling them.

\section{References}

Bock SA, Sampson HA, Atkins FM, Zeiger RS, Lehrer S, Sachs M, Bush RK \& Metcalfe DD (1988) Double-blind placebocontrolled food challenge (DBPCFC) as an office procedure: a manual. Journal of Allergy and Clinical Immunology 82, 986-997.

European Commission (2003) Directive 2003/89/EC of the European Parliament and of the Council of 10 November 2003 amending Directive 2000/13/EC as regards indication of the ingredients present in foodstuffs. Official Journal of the European Communities L308, 15-18.

Grundy J, Matthews S, Bateman B, Dean T \& Arshad SH (2002) Rising prevalence of allergy to peanut in children: Data from 2 sequential cohorts. Journal of Allergy and Clinical Immunology 110, 784-789.

Hill DJ \& Hosking CS (1995) The Cows milk allergy complex: overlapping disease profiles in infancy. European Journal of Clinical Nutrition 49, Suppl. 1, S1-S12.

Johansson SGO, Bieber T, Dahl R, Friedmann PS, Lanier BQ, Lockey RF et al. (2004) Revised nomenclature for allergy for global use: Report of the Nomenclature Review Committee of the World Allergy Organization, October 2003. Journal of Allergy and Clinical Immunology 113, 832-836.

Royal College of Physicians (2003) Allergy - The Unmet Need. A Blueprint for Better Patient Care. London: Royal College of Physicians.

Sampson HA \& Scanlon SM (1989) Natural history of food hypersensitivity in children with atopic dermatitis. Journal of Pediatrics 115, 23-27.

Skolnick HS, Conover-Walker MK, Koerner CB, Sampson HA, Burks W \& Wood RA (2001) The natural history of peanut allergy. Journal of Allergy and Clinical Immunology 107, 367-374. 